\title{
Special Issue on Selected Articles from the Proceedings of the 2006 Denver X-ray Conference \& Powder Diffraction Notes for Authors
}

In early 2003, Powder Diffraction and the Denver X-ray Conference agreed to a collaboration to publish selected articles from the proceedings of the Denver X-ray Conference, Advances in X-ray Analysis, in Powder Diffraction. This collaboration has led to the advance publication of 56 highquality articles from Volumes 47, 48, and 49 of Advances in $X$-ray Analysis in the March 2004, June 2005, and June 2006 issues of Powder Diffraction. The CD-ROMs of Volumes 47, 48 , and 49 were also distributed to the institutional print and print/online subscribers of Powder Diffraction. This collaboration has significantly increased services and the number of articles available to Powder Diffraction subscribers, as well as the circulation for the authors of Advances in X-ray Analysis.

Since this collaboration has been well received from the X-ray analysis community, Powder Diffraction is delighted to continue this practice and annually publish selected articles from the proceedings of the Denver X-ray Conference in the June issue of Powder Diffraction.

This issue of Powder Diffraction is dedicated to selected high-quality articles from Advances in X-ray AnalysisVolume 50, Proceedings of the 55th Annual Conference on Applications of X-ray Analysis. The 2006 Denver X-ray Conference was held in Denver, Colorado from 7-11 August 2006, and attracted over 300 registered attendees and over 200 exhibit personnel.

Conference week began with 16 tutorial workshops, held on Monday and Tuesday. Topics included Specimen Preparation XRD, Rietveld Applications-Beginner, Basic Crystal- lography, Rietveld Applications-Advance, High Resolution XRD, New Generation of XRD Database I and II, Microbeam X-ray Characterization I and II, Specimen Preparation XRF I and II, Basic XRF, Trace Element Analysis, EDXRF, and Quantitative XRF I and II.

A plenary session on Medical Applications of X-ray Analysis and fifteen special technical sessions filled the remaining three days of the conference. Topics for the special technical sessions included New Developments in XRD and XRF Instrumentation, In-situ Characterization, Thin Films, X-ray Optics, Detectors and Sources, Environmental and Archaeological Applications, Structure Solution and Refinement, Applications of High Energy X-rays I and II, Industrial Applications of XRD, Stress Analysis, Quantitative XRF, New Developments and Industrial Applications of XRF, Trace Analysis, and Fusion Applications.

Finally I would like to thank the editors of Advances in $X$-ray Analysis, John Anzelmo, Victor Buhrke, John Gilfrich, Cev Noyan, and Robert Snyder for selecting and editing the articles that appear in this special issue of Powder Diffraction.

In addition, the updated Notes for Authors appears in this issue, which may also be viewed at ICDD's website. Authors are encouraged to review this document prior to preparing and submitting papers to Powder Diffraction.

Ting C. Huang

Editor-in-Chief 